\title{
Bar pressing by the rat as a function of auditory stimulation'
}

\. J. LAVERY AND P. J. FOLEY

DEFENCE RESEARCH MEDICAL LABORATORIES, TORONTO, CANADA

\begin{abstract}
Abstraet
The experiment shows the rate of bar pressing by the rat as a function of four ambient white noise levels, when a bar press interrupts the noise for $15 \mathrm{sec}$. The results indicate an inverted $U$-shaped relation at the beginning of the experiment. As successive exposures to white noise take place, the relation changes progressively to a linear one. These findings support the sensory reinforcement hypothesis, and are discussed in relation to an a priori distinction between stimulus and drive. It is suggested that the same state may serve as both. Two theoretical explanations can explain these findings. Problem
\end{abstract}

Barnes \& Kish (1957) have shown that when depression of a platform interrupts a white noise, rats exposed to the noise will spend considerably more time on the platform than rats not exposed to it. Similarly, Lavery \& Foley (1963) have shown that rats will press a bar to interrupt white noise. Each of these studies used a specific level of white noise. The purpose of the present experiment was to determine the functional relation between noise level and this type of behavior. The study examined the frequency of bar pressing as a function of the ambient level of white noise, when each bar press interrupted the noise for $15 \mathrm{sec}$.

\section{Method}

The experimental box, 11 in wide, 12 in long, and 8.5 in deep, was made from 0.5 in plywood, with a metal grid floor and ceiling. The horizontal part of a T-shaped metal bar, 3.25 in long, and of square cross section 0.25 in on the side, protruded 1 in into the box through the floor 0.75 in from one end wall. The vertical stem of the $\mathrm{T}$-shaped bar was connected outside the box to a microswitch which was operated by gentle pressure against the T-bar. The microswitch was in turn connected to Hunter timers and an Esterline-Angus recorder.

The white noise was produced by a Grason-Stadler generator, No. 455B, connected to a MacIntosh 75 watt power amplifier, which fed a 15 in speaker Altec 604. The speaker was mounted in a plywood enclosure supported on four legs, each 12 in high. The experimental box could be placed under the enclosure, and hence directly under the speaker. The noise level at the center of the experimental box placed directly under the speaker was measured in decibels re $0.0002 \mathrm{dyne} / \mathrm{cm}^{2}$ with a sound level meter (H.H. Scott model 410B).

The present experiment followed two pilot studies. The previous studies allowed us to determine the range of noise levels to study. They revealed that any sound level at or below the ambient noise (62 db) level of the room in which the animals were kept produced a steady rate of 2 to 3 bar presses per session with no increment through 10 days. Therefore, four levels of noise were used in the present experiment with increments of 12 $\mathrm{db}$ over the ambient noise level, i.e., 74, 86, 98 and $110 \mathrm{db}$ re 0.0002 dyne $/ \mathrm{cm}^{2}$.

A total of 20 male rats of the Wistar strain were used, five for each group. Each group was subjected to one noise level. For 28 consecutive days prior to the experiment, each of 20 rats was handled for a 10 min. period each day.

During any experimental session the rat was placed in the experimental box and exposed for $10 \mathrm{~min}$. to a selected constant level of white noise. If the rat pressed the bar, the noise was interrupted for $15 \mathrm{sec}$. Depressions of the bar during a $15 \mathrm{sec}$. quiet period resulted in additional quiet periods of $15 \mathrm{sec}$.

Each group was tested until its frequency of bar pressing reached a constant value. As a result the 74 and $86 \mathrm{db}$ groups were run for 17 consecutive days, and the 98 and $110 \mathrm{db}$ groups were run for 29 consecutive days.

\section{Results}

The results are shown schematically in Fig. 1. Although most Ss showed an increase in bar pressing not all the Ss did: two Ss in each of the 74, 86110 $\mathrm{db}$ groups averaged less than one bar press per

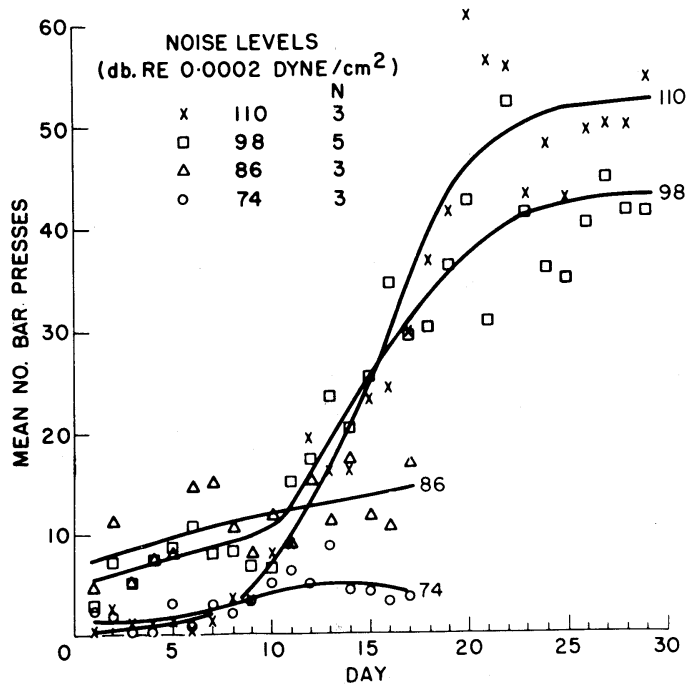

Fig. 1. Schematic representation of the functional relation between bar pressing and noise level 
session even after the others in the group had reached an asymptote. The $110 \mathrm{db}$ group did not show an appreciable increase in frequency of bar pressing before the twelfth day. Eventually, however, the pərformance of this group reached a much higher level than that of the other three groups.

\section{Diseussion}

When different rats are first exposed to various intensities of noise and allowed to interrupt the noise by pressing a bar, bar pressing is a function of the intensity of the noise up to a certain level after which the bar-pressing rate decreases. This is the inverted U-shaped relation commonly associated with arousal phenomena.

Secondly, if the rats are exposed to the same noise intensity for a number of successive sessions, the bar-pressing rate remains virtually unchanged for low intensity noise, increases immediately but gradually for intermediate intensities, and increases belatedly but rapidly for high intensities, so that after an adequate period of exposure, a direct relation between frequency of bar pressing and noise intensity is obtained.

These findings support the sensory reinforcement hypothesis. While most animals prefer some stimulation (Keller, 1941; Girdner, 1953; Marx, Henderson \& Roberts, 1955), most choose no stimulation in preference to strong stimulation (Barnes \& Kish, 1957).

The present results offer some support to the suggestion (Barnes \& Kish, 1957) that it may be unnecessary to consider drive and stimulus as having separate objects. At the beginning of the experiment the white noise produced the effects associated with a drive: low intensity of stimulation showed no change in bar-pressing frequency, the intermediate intensity showed immediate increase and the high again produced no change in behavior. As exposure to noise was prolonged the animals presumably adapted to the high stimulation, causing a decrease in drive level which allowed the bar-pressing response to be learned. Once the response was learned the noise served as a stimulus. This suggests that the same variable can behave both as a drive and a stimulus, and argues against an a priori distinction of some states as drives, and others as stimuli. The two-factor theory of avoidance learning (Mowrer, 1947, 1951; Solomon \& Wynn, 1954) can explain the present results. It proposes that two processes are involved in avoidance learning. The first is a classical conditioning process. The noxious stimulation produces a conditioned emotional response. The second is an instrumental learning process. The animal learns to avoid the noxious stimulus. This latter response varies with stimulus intensity in a manner predicted by arousal theory: learning is best at an intermediate level of stimulation. The conditioned emotional response, if one could measure it without the instrumental, would presumably vary directly with the unconditioned stimulus as suggested by Brush (1957).

Although we did not make use of a conditioned stimulus, we may nevertheless assume the presence of an emotional response such as fear caused by the noise. This response would provide the motivation for learning to press the bar. Once the bar pressing is learned, the emotional response is expressed by the frequency of bar pressing which is a direct function of noise intensity.

A second explanation of the present findings might be found in Bindra's second generalization on arousal (Bindra, 1959). The first generalization describes the inverted-U relation between drive and performance; the second generalization states that both the total range of arousal and optimal level increase with practice. In the present situation this would mean that the optimal level shifted from $74 \mathrm{db}$ on the first day to $110 \mathrm{db}$ on the 29th day, and that the total range extended beyond the conditions of the experiment. Perhaps a better way of testing this hypothesis would be to submit all rats to all the various levels with different groups starting at the various pre-determined levels. This would allow better differentiation of the effect of noise level from that of duration of exposure.

\section{References}

Barnes, G. W., \& isish, G. B. Reinforcing properties of the termination of intense auditory stimulation. $J$. comp. physiol. Psychol., 1957, 50, 40-43.

Bindra, D. Motivation: a systematic reinterpretation. New York: Ronald Press, 1959

Brush, F. R. The effects of shock intensity on the acquisition and extinction of an avoidance response in dogs. J. comp. physiol. Psychol., 1957, 50, 547-552.

Girdner, J. B. An experimental analysis of the behavioral effects of a perceptual consequence unrelated to organic drive states. Unpublished Ph.D. dissertation, Duke University, 1953.

Keller, F. S. Light aversion in the white rat. Psychol. Rec., 1941, $4,235-250$.

Lavery, J. J., \& Foley, P. J. Altruism or arousal in the rat? Science, 1963, 140, 172-173.

Marx, M. H., Henderson, R. L., \& Roberts, C. L. Positive reinforcement of the bar-pressing response by a light stimulus following dark operant pretests with no after effect. J. comp. physiol. Psychol., 1955, 48, 73-76.

Mowrer, $\mathbf{0}$. H. On the dual nature of learning: a reinterpretation of "conditioning" and "problem solving." Harvard educ. Rev., 1947, 17, 102-148.

Mowrer, O. H. Two-factor learning theory: summary and comment. Psychol. Rev., 1951, 58, 350-354.

Solomon, R. L., \& Wynne, L. C. Traumatic avoidance learning: the principles of anxiety conservation and partial irreversibility. Psychol. Rev., 1954, 61, 353-385.

Note

1. Defence Research Medical Laboratories Research Paper No. 583, PCC No. D50-89-01-01. 